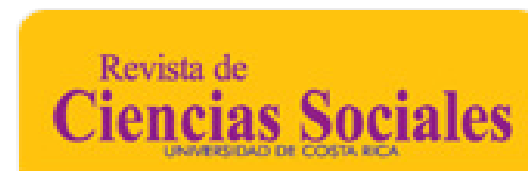

\section{Voorend, Koen; Venegas Bermúdez, Karla \\ TRAS DE CUERNOS, PALOS. PERCEPCIONES SOBRE COSTA RICA COMO IMÁN DE BIENESTAR EN LA CRISIS DEL SEGURO SOCIAL}

Revista de Ciencias Sociales (Cr), vol. III, núm. 145, 2014, pp. 13-33

Universidad de Costa Rica

San José, Costa Rica
Revista de Ciencias Sociales (Cr)

revista.cs@ucr.ac.cr

Universidad de Costa Rica

Costa Rica

Disponible en: http://www.redalyc.org/articulo.oa?id=15333873003

- Cómo citar el artículo

- Número completo

- Más información del artículo

- Página de la revista en redalyc.org 


\title{
TRAS DE CUERNOS, PALOS. PERCEPCIONES SOBRE COSTA RICA COMO IMÁN DE BIENESTAR EN LA CRISIS DEL SEGURO SOCIAL ${ }^{1}$
}

\section{FROM THE FRYING PAN INTO THE FIRE. PERCEPTIONS OF COSTA RICA AS A WELFARE MAGNET IN THE CONTEXT OF A SOCIAL SECURITY CRISIS}

\author{
Koen Voorend * \\ Karla Venegas Bermúdez **
}

RESUMEN

En el contexto de una crisis de la institución emblemática del régimen de protección social costarricense, la Caja Costarricense del Seguro Social (ccss), la integración de la población inmigrante nicaragüense se vuelve aún más polémica. Como respuesta, el Estado costarricense, a través de reformas a la Ley de Migración, así como de nuevas y viejas políticas dentro de la misma ccss, crea nuevas fronteras alrededor de la salud, haciendo más difícil el acceso para inmigrantes. Para entender estas reacciones, se analiza la importancia de la construcción social del sujeto inmigrante desde las instituciones estatales de política social. Con base en una serie de entrevistas con funcionarios públicos, se demuestra que existe una fuerte percepción de Costa Rica como "imán de bienestar", la migración vista como un 'mal necesario' y que se cuestiona la legitimidad de la demanda de servicios de salud de la población nicaragüense a partir de la percibida "ilegalidad" de la misma.

PALABRAS CLAVE: INMIGRACIÓN * PERCEPCIÓN * POLÍTICA SOCIAL * POLÍTICA MIGRATORIA * BIENESTAR SOCIAL

\section{ABSTRACT}

In the context of a crisis of the flagship institution of Costa Rica's social protection system, the Caja Costarricense del Seguro Social, the integration of Nicaraguan immigrants has become even more controversial. The State's reaction, through reforms to the Migration Law and new and revived policies within the cCSs, has been to create boundaries around

1 Agradezco mucho la asistencia de Karla Venegas Bermúdez, quien ayudó con las entrevistas, así como, el procesamiento de la información. Además, se agradece mucho la revisión de una persona comentarista anónima.

Instituto de Investigaciones Sociales (IIS) de la Universidad de Costa Rica (UCR).

koenvoorend@gmail.com

** Programa Servicios Financieros para la Agricultura Sostenible (sefas).

karla.venegasbermudez@gmail.com 
health services, making access more difficult for immigrants. To understand these reactions, we argue that it is important to analyze the social construction of the immigrant subject by public social policy institutions. Based on a series of interviews with public officials, we show that there is a strong perception of Costa Rica being a "welfare magnet", migration is seen as a "necessary evil" and that the legitimacy of Nicaraguan immigrants' demand for health services is questioned based on their perceived "illegality".

KEYWORDS: IMMIGRATION * PERCEPTION * SOCIAL POLICY * MIGRATION POLICY * SOCIAL WELFARE

... es mejor ser pobre aquí que pobre en sus países.

Dirección de Inspección, $\operatorname{ccss}^{2}$.

\section{INTRODUCCIÓN}

El 31 de octubre de 2012, la Caja Costarricense de Seguro Social (ccss), institución de seguridad social, emitió una directriz interna que representa "-el ataque más grande en las últimas décadas" (Carlos Sandoval, investigador, Instituto de Investigaciones Sociales de la Universidad de Costa Rica, entrevista 23/04/2013) al principio de universalismo que caracteriza el régimen de protección social costarricense (Voorend, 2013). En la comunicación, emitida por Eduardo Flores Castro, Jefe del Departamento de Cobertura del Estado, se cuestiona el derecho al acceso a servicios de salud prenatal de mujeres extranjeras embarazadas sin documentos. En específico, la comunicación aclara que mujeres embarazadas extranjeras con identificación pero con una condición migratoria irregular (pasaporte válido, pero visa de turista vencida), "se aplica la Ley 7739 como protección al menor, otorgándose el carné con código de aseguramiento 000, hasta por el período de lactancia" (ccss, 2012a: 1). Sin embargo, estipula que las mujeres embarazadas no identificadas en:

... aquellos casos en los cuales no portan ningún documento reconocido en el país como identificación (...) o bien estos están vencidos, se aplica lo establecido en el artículo 74 del Reglamento

Comunicación personal, 29 de abril de 2013. de Salud, esto significa que una persona no identificada solo puede acceder a los servicios que brinda la Caja en condición de urgencia o emergencia (idem).

Si bien, existe discusión sobre cuán universal es el régimen de política social costarricense (López, 2012; Martínez y Sánchez, 2013), hasta este momento no se había cuestionado el acceso a la salud, verdaderamente universal, para algunos grupos especiales "cuya membresía en el ámbito de la seguridad social no se basa en la afiliación con ningún tipo de seguro público" (López, 2012: 127. Traducción propia). Para niños y niñas, mujeres embarazadas, mujeres maltratadas $y$ personas portadoras de enfermedades infecciosas, el Estado costarricense reconoce el derecho universal e irrevocable a la asistencia sanitaria. En el caso específico de mujeres embarazadas, aplica el Código de Niñez y Adolescencia y la Ley General de Protección a la Madre Adolescente (Ley nro. 7735), las cuales reconocen el derecho universal e innegable (a la salud) de las niñas y niños nacidos y por nacer. Como lo expresa Flores: "-las mujeres embarazadas están mejor protegidas que el Banco Central” (Eduardo Flores, Jefe Cobertura del Estado, ccss, entrevista, 24/04/2013). Este ataque al universalismo costarricense $e^{3}$ es emblemático para

3

Afortunadamente, tras una solicitud de la Defensoría de los Habitantes de explicar esta medida y la presión de ongs, como, el Servicio Jesuita para los Migrantes, la ccss retiró sus intenciones en una comunicación con fecha del 10 de mayo de 2013, en la que se anuló la anterior directiva (ccss, 2013b). 
un proceso de construcción social colectiva del sujeto inmigrante como amenaza a la anteriormente vulnerada seguridad social costarricense. Ante la crisis de la ccss, institución emblemática de la política social universal y solidaria costarricense, la reacción de la política pública ha sido la construcción $y$ la movilización de fronteras en torno a cuestiones de distribución de los recursos del estado de bienestar (Voorend, 2013) como es común en situaciones de crisis económica, política y social (Faist, 1994).

Para entender los procesos sociales, las políticas públicas en general y la creación de límites al universalismo en particular, es importante analizar la construcción social del sujeto inmigrante desde las instituciones estatales de política social, reconociendo que "los migrantes son sujetos sociales que actúan en circunstancias históricas y coyunturas específicas" (Feldman-Bianco, Rivera, Stefoni y Villa, 2011:17). Reconociendo que buena parte de la política social "depende de la persona que esté en ventanilla" (Dobles, Vargas y Amador, 2014) $y$ dado que son los actores quienes componen las instituciones e implementan sus políticas, el presente artículo constituye un acercamiento a las narrativas de los actores sobre los derechos sociales de la población inmigrante que componen el engranaje de la institución de la ccss $y$ analiza cómo estas narrativas pueden formar obstáculos en el acceso a servicios de salud para los inmigrantes en Costa Rica.

Con base en 17 entrevistas con funcionarios de la ccss y de la Dirección General de Migración y Extranjería (DGME), realizadas entre el 19 de marzo y el 23 de mayo de 2013, este artículo propone caracterizar algunas concepciones sobre la población inmigrante nicaragüense en Costa Rica, su derecho a la salud y la sostenibilidad financiera de la ccss, así como, las percepciones del sistema de protección social en general. La discusión se centra en la legitimidad percibida de la demanda de servicios de salud por extranjeros y su derecho a la salud.

Primeramente, se consideran en este documento, algunos insumos para la discusión sobre la idea de Costa Rica como imán de bienestar, el universalismo como principio que guía la política social en la práctica en tres diferentes niveles: la política, las directivas y en su aplicación. Segundo, se presenta el contexto de inmigración en Costa Rica, la reforma de la Ley de Migración de 2009 y la crisis de la ccss de 2011. Tercero, se presenta el análisis sobre las percepciones de los actores, enfocándose en la idea de Costa Rica como imán de bienestar, la legitimidad de la demanda de parte de la población inmigrante de servicios de salud, la Ley nro. 8764 y el endurecimiento de las políticas de la Caja. En la última sección se presentan algunas reflexiones finales.

\section{MIGRACIÓN, REFORMA DE LEY Y SALUD}

\section{A) LA POLÉMICA RELACIÓN MIGRACIÓN-SALUD EN COSTA RICA}

En la actualidad, la población inmigrante representa alrededor del 9\% de la población total en Costa Rica, de la cual alrededor del $75 \%$ proviene de Nicaragua, según datos oficiales del INEC (2011), sin incluir un número desconocido de inmigrantes irregulares $y$ temporales (Voorend, 2013). Con esto, en términos relativos, Costa Rica es el país con más inmigración en América Latina (Voorend, 2013), atrayendo principalmente, inmigrantes de baja calificación que se insertan en la agricultura (hombres y mujeres), la construcción (hombres) y el servicio doméstico (mujeres) (Morales y Castro, 2006; Sandoval, 2008). Durante la primera década del 2000, Costa Rica representaba el primer destino para la población migrante nicaragüense, seguido por los Estados Unidos (EEUU) (Baumeister, Fernández y Acuña, 2008; Acuña, Herra y Voorend, 2013).

La incorporación social de inmigrantes, especialmente nicaragüenses, ha sido polémica (Voorend, 2013; Sandoval, 2008 y 2013). En el imaginario social de tres cuartas partes de la población costarricense, existe la idea persistente de que los inmigrantes nicaragüenses constituyen un riesgo para la seguridad social del país (González y Varela, citado en Bonilla-Carrión, 2007). Así, existe una percepción que las personas inmigrantes nicaragüenses son más propensas a hacer uso de los servicios sociales públicos, porque se asume que son "irregulares" 
$y$ tienen bajos niveles educativos (Bonilla-Carrión, 2007: 146). Aunque una buena parte de la población inmigrante cuenta con algún tipo de cobertura del seguro social (65\%) (INEC, 2011), se cree que están sobre representados como usuarios de servicios sociales, especialmente en los servicios de salud pública. Estas percepciones se convierten en argumentos importantes contra la inmigración nicaragüense.

Esta situación se agudizó mayormente en el 2011, cuando la ccss entró en una crisis financiera que ha puesto en tela de juicio la sostenibilidad de la institución (Carrillo, Martínez, Naranjo y Sauma, 2011). La ccss se creó en 1941, como una institución de seguridad social y como principal proveedor de servicios de salud en Costa Rica. Inicialmente, se proporcionaban estos servicios solo a trabajadores formales, pero en 1961, se incluyeron los miembros de sus familias como dependientes. Desde entonces, su cobertura se ha extendido a toda la población, incluidos los grupos no contributivos y actualmente, la institución cubre con eficacia alrededor del 85\% de los costarricenses (Noy, 2012 y Martínez, 2008a).

Sin embargo, desde los años 70 y 80 , cuando cambiaron los paradigmas de la política social con la implementación de las políticas del llamado Consenso de Washington y por las estrictas limitaciones de los presupuestos públicos, el Estado estaba en una posición más débil para ofrecer protección social (Martínez, 2008a y 2008b). En el 2008, la crisis financiera lleva a una desaceleración de la economía costarricense, dado que la ccss es una institución que se financia a través de un sistema tripartito (Estado, patrones y trabajadores), esta desaceleración afecta a la institución directamente a través del porcentaje de $11 \%$ del Producto Interno Bruto (PIB) $(7 \%$ de salud y $4 \%$ de pensiones); no obstante, también a través del aumento del desempleo y la informalidad en el mercado laboral, lo cual disminuyó los ingresos de los trabajadores. Sin embargo, la crisis de la ccss se debe principalmente a aumentos en la planilla, subidas de los costos y de los salarios, así como la mala gestión de la cCss en los años anteriores (oPs, 2011). Asimismo, la crisis de la ccss presenta una situación más aguda (y mediatizada) que si bien, no existe ninguna evidencia de que esta crisis fuese causada por la demanda de servicios de salud por parte de la población inmigrante, esto pone en tela de juicio la legitimidad percibida de la demanda de servicios de salud de extranjeros.

\section{B) REFORMA DE LEY: ¿MÁS O MENOS ACCESO A LA CCSS?}

En julio de 2009, la Ley General de Migración y Extranjería (nro. 8764), fue aprobada por la Asamblea Legislativa y entró en vigencia en marzo de 2010. Esta ley se inserta en un vocabulario de derechos humanos, haciendo múltiples referencias a los tratados internacionales suscritos por Costa Rica (Voorend, 2013; Kron, 2011; López, 2012 y Sandoval, inédito) e incorpora por primera vez el concepto de integración, poniendo énfasis en la importancia de la inclusión de inmigrantes en la sociedad costarricense (López, 2012 y Kron, 2011).

Sin embargo, entre varias críticas importantes hacia la Ley y a la política migratoria costarricense (Instituto de Investigaciones Sociales-IIs, Centro de Investigación en Cultura y Desarrollo, Programa Radiofónico Casa Abierta 870 UCR y Servicio Jesuita para Migrantes Costa Rica, 2012; Voorend, 2013 y Sandoval, inédito), es notable que esta establece la afiliación al sistema público de seguridad social como uno de los nuevos requisitos para iniciar el proceso de regularización del estado migratorio. Específicamente, la Ley plantea que:

... la tramitación de toda gestión migratoria deberá garantizar el aseguramiento a la seguridad social por parte de las personas migrantes. Tal garantía obligará a que todo trámite migratorio deba contemplar, como uno de sus requisitos básicos, contar con los seguros que brinda la Caja Costarricense de Seguro Social (cCss) (Ley nro. 8764; artículo 7-inciso 7).

Este requisito ha sido criticado por no fomentar la regularización (Sandoval, inédito y Voorend, 2013) y por hacer más difícil el acceso a los servicios que brinda la ccss (Voorend, 2013). Al mismo tiempo, a partir de una solicitud de la DGME (Voorend, 2013), la cCss comunica 
que "las personas extranjeras que solicitan el aseguramiento para efectos de renovar su residencia, deben presentar la cédula de residencia vigente", o tienen que mostrar que todos los papeles para el estado migratorio regular están en trámite, en caso de que se pueda dar un aseguramiento temporal de hasta dos meses (ccss, 2012a: 1). Con esto, la interacción de DGME $y$ la cCss crea una situación sin salida para inmigrantes considerados como "ilegales"4 $y$ dificulta el acceso a la política social, en especial el sector de la salud. Así, en lo referente a los servicios de salud, se trata de minimizar la demanda percibida como ilegítima de la población inmigrante no regular (López, 2012).

\section{3. ¿UNIVERSALISMO COMO IMÁN DE BIENESTAR?}

\section{A) INMIGRACIÓN COMO AMENAZA}

En términos generales, tanto la literatura económica como sociológica que analiza la relación entre migración y la política social, tiende a conceptualizar la población inmigrante como una amenaza para la sostenibilidad de los estados de bienestar generosos (Van Oorschot, 2008). Los argumentos se centran, primero, en la idea de los fuertes regímenes de política social como imanes de bienestar, y segundo, en la posibilidad de que la inmigración conlleve a una pérdida de legitimidad social de las políticas de bienestar.

El primer argumento se da especialmente, cuando la población inmigrante depende de manera desproporcionada de las prestaciones sociales; es decir, tiene una incidencia relativamente alta en políticas públicas (Borjas, 1994; Borjas y Hilton 1996; Van Oorschot, 2008; Boeri, Hanson y McCormick, 2002; Muenz y Fassmann, 2004) o bien, cuando personas migran a países con regímenes de política social avanzados (Borjas, 1998; Schram y Soss, 1999;

Nadie es ilegal y a través de los derechos humanos, todas las personas tienen derechos irrevocables, sin importar su estado migratorio. Sin embargo, en este documento se usa el término "ilegal" para reflejar el uso común en los discursos de los funcionarios públicos de diferentes rangos.
De Jong y Graefe, 2002). En ambos casos, la literatura sobre el nexo migración-política social tiende a conceptualizar las prestaciones sociales como un factor que podría atraer inmigración, constituyendo así un imán y advierte sobre los altos costos en términos del gasto social que podría implicar la inmigración, lo que podría poner en peligro la sostenibilidad financiera de los sistemas de bienestar a largo plazo. Sin embargo, esta advertencia no se sostiene en evidencia empírica sustantiva (Van Oorschot, 2008; Hujo y Piper, 2010).

El segundo argumento sostiene que la inmigración socava la legitimidad social de políticas sociales solidarias y comprensivas. Siguiendo la teoría de los recursos de poder, el pluralismo cultural que implica la inmigración al aumentar el grado de diversidad étnica, lingüística o racial, tiene el potencial de debilitar las coaliciones de clase más amplias asociadas a los estados de bienestar mediante la división del trabajo (Banting, 2000). Así, la inmigración podría debilitar los acuerdos sociales de bienestar (Freeman, 1986 y Van Oorschot, 2008). Además, la inmigración podría reforzar la conciencia de las diferencias de identidad entre "nosotros" y "los otros", desgastando así el consenso normativo sobre la redistribución del bienestar (Van Oorschot, 2008). Sin embargo, nuevamente, la evidencia empírica para ambos argumentos es débil (Banting, 2000; McCarty, 1993; James, 1993; Easterly y Levine, 1997).

Para este caso, en cuanto a la pregunta de si los y las inmigrantes escogen Costa Rica como país de destino por el acceso al régimen de política social que el proceso de migración podría implicar, no existen estudios que lo confirman o rechazan. La mayor parte de la literatura sobre la migración nicaragüense en Costa Rica pone énfasis en su componente laboral, sin profundizar mucho en el nexo migraciónpolítica social. Se conoce relativamente poco sobre el acceso real a la política social por parte de las poblaciones inmigrantes. En cuanto a la 'sobrerrepresentación' de inmigrantes en programas de asistencia social del Estado, Castillo (2003) proporciona un análisis de incidencia simple, que muestra que en el 2002, la población inmigrante representaba entre 
$4 \%$ y $6,3 \%$ de servicios de la ccss para ese año. Esto es menos que proporcional a la población extranjera total registrada en las Encuestas de Hogares del $2002(6,91 \%)$ y no proporciona ningún análisis sobre las contribuciones que hace esta población al seguro social.

Es cierto que en algunos programas de la ccss, como los beneficiarios cubiertos por el Estado (20\% en 2012) o los partos intrahospitalarios (16\% en 2012) de la población inmigrante (ccss, 2012), su explicación se vincula más con las características socio-económicas de esta población que su estado migratorio. Efectivamente, Bonilla-Carrión (2007) muestra que un hogar nicaragüense promedio hace mayor uso de los servicios sociales que un hogar costarricense, pero también invierte más en estos servicios. También existen estudios que demuestran que la población inmigrante contribuye más a la seguridad social de lo que realmente usa de estos servicios (Bravo, 2009 y DGME, 2011), pero no existen estudios integrales que analizan el nexo migración-política social a profundidad.

A pesar de esta escasez de evidencia empírica, en el discurso popular la idea del país como imán de bienestar es muy común (Voorend 2013; López, 2012 y Bonilla-Carrión, 2008). Como se demostrará, estas ideas existen también entre funcionarios de las instituciones estatales, lo cual tiene implicaciones para la legitimidad percibida de la demanda de servicios de salud, el nivel y el tipo de acceso a la política social por parte de la población inmigrante.

\section{B) ¿EL UNIVERSALISMO COMO ATRACCIÓN?}

En el discurso popular, el carácter universal y solidario de la política social costarricense podría explicar parte de esta atracción. Los principios de universalismo y solidaridad podrían ser un factor que la persona inmigrante tome en cuenta en el momento de tomar su decisión de migrar (Hujo y Piper, 2010). Efectivamente, la política social, entendida como intervenciones públicas que tienen como objetivo evitar que personas sufran una disminución de sus ingresos y sus oportunidades de vida, mientras que promueve activamente condiciones de vida $y$ trabajo decentes para todos, tiene un papel central en la incorporación (social y económica) de las y los inmigrantes. La política social es uno de los principales mecanismos de integración o segregación dentro de las sociedades (Fischer, 2009 y Mkandawire, 2005).

Existe el debate sobre cuál enfoque de modo de prestación es más efectivo (Fischer, 2009; Danson, McAlpine, Spicker y Sullivan, 2012), pero parecen existir ventajas del universalismo sobre otros enfoques de la política social, como la focalización en cuanto a su poder de redistribución. La focalización arraiga segmentación en los sistemas de prestación, que a su vez refuerza la estratificación social y económica mediante la eliminación de las clases medias y su voz política de los servicios que se suministran (Fischer, 2009). En contraste, la universalidad tiene varias ventajas importantes. Primero, políticas sociales universales, entendidas como aquellas que alcanzan a toda la población con transferencias generosas similares y servicios de alta calidad (Martínez y Sánchez, 2013), la clase media estaría más dispuesta a apoyar programas sociales y su financiamiento, independientemente de si están diseñados para grupos específicos o para la población en general. Además, esta alianza entre clases, no solo favorece la cobertura, sino también la calidad (idem). Así, las políticas sociales universales tienen más impacto sobre pobreza, vulnerabilidad $y$ desigualdad (Fischer, $2009 y$ Mkandawire, 2005). Finalmente, personas con niveles de ingreso y características personales muy diferentes terminan compartiendo un tratamiento similar basado en su condición de ciudadanos.

Sin embargo, el que sean políticas sociales universales no significa que se asegure el acceso a ellas por parte de la población inmigrante. Si se entiende el derecho al acceso a servicios de bienestar como un derecho de ciudadanía (Lister, 1990), podría llegar solo a los ciudadanos (Danson, McAlpine, Spicker y Sullivan, 2012) y así excluir a inmigrantes, incluso los documentados. Además, países con prestaciones sociales más generosas y más accesibles también podrían ser más cuidadosos de estos beneficios (Faist, 1996). Como plantea Hollifield (2000) y como demuestra Voorend 
(2013) para Costa Rica en particular, países con fuertes regímenes de política social pueden funcionar como un "arma de doble filo: puede facilitar la incorporación de los inmigrantes, pero también puede funcionar como un mecanismo eficaz para el control de la inmigración" (p.109) del Estado y la política social convertirse en "un blanco para aquellos que deseen restringir los derechos de los extranjeros como una forma de control migratorio" (p.113).

\section{C) PERCEPCIONES Y NARRATIVAS}

Crear límites en torno a la distribución de recursos de bienestar es relativamente común en tiempos de crisis (Faist, 1996), pero pocas veces se fundamenta más en percepciones sobre la inmigración como una amenaza que en datos duros que muestran que la población inmigrante efectivamente causa o forma parte de la crisis. Para entender procesos de políticas públicas que afecten a las y los inmigrantes, $y$ su implementación, es importante analizar la construcción social del sujeto inmigrante desde las instituciones estatales de política social, reconociendo que "los migrantes son sujetos sociales que actúan en circunstancias históricas y coyunturas específicas" (Feldman-Bianco, Rivera, Stefoni y Villa, 2011: 17). En esta contribución, se ahonda en medidas restrictivas tomadas por Costa Rica desde las narrativas de los funcionarios de la CCSS y DGME articulados en tres ejes: funcionarios públicos de alto rango $y$ asesores de política, profesionales en salud pública $y$ funcionarios de nivel operativo.

Estas narrativas son importantes como expresiones de percepciones. Siguiendo a Bourdieu (2000), según las posiciones ocupadas en el espacio social, un agente adquiere un sistema de disposiciones por aprendizaje implícito o explícito, el cual "es generador de estrategias que pueden ser objetivamente conformes con los intereses objetivos de sus autores sin haber sido expresamente concebidas con ese fin" (Bourdieu, 2000: 119).Un individuo actúa dentro de un habitus, entendido como un sistema de esquemas de producción de prácticas, de percepciones y apreciaciones, según su posición.

Reguillo (2000) propone varias dimensiones de estudio que son útiles como punto de partida para el análisis que se propone. Primero, como formación discursiva, en este caso se encuentra el universalismo en la política social, al ser este una formación histórica culturalmente compartida y subjetivamente interpretada. Segundo, el campo de discursividad es el espacio social en el que se ubica el individuo y que brinda las condiciones de producción del discurso; al trabajar con la ccss, se está enfoncando en el campo de la salud pública. Tercero, las estrategias discursivas consisten en el ámbito de decisión que tiene el agente desde su respectiva posición en el campo de discursividad, es decir, en el espacio social. Estas estrategias se concretan en el plano del relato por medio de narrativas, dimensión en la cual se enfoca explícitamente para analizar la concreción de estrategias narrativas de funcionarios de la ccss.

En la sección siguiente, se analiza estas narrativas con base en dos fuentes. Primero, se hizo una serie de 17 entrevistas, principalmente con funcionarios de la CCSS y la DGME sobre la legitimidad percibida de la demanda de servicios de salud por parte de inmigrantes nicaragüenses, el acceso que tiene esta población a la salud $y$ la política migratoria $y$ de salud que podría facilitar o restringir este acceso. Se entrevistaron asesores técnico-políticos que formaron parte de la reforma de Ley de Migración, funcionarios a cargo de emitir directrices en la ccss, así como, personas a nivel de ejecución de estas leyes y directrices. Es de interés el conocer narrativas, entendidas de aquí en adelante como las expresiones de las percepciones de las personas, a ambos niveles; es decir, interesan tanto las percepciones de quienes tienen un efecto directo sobre la formación de política pública, como las percepciones de aquellos que las ejecutan diariamente ${ }^{5}$. Segundo, se basa en algunas directrices internas de la ccss, así como, en la Ley de Migración nro. 8764. Estos documentos forman la concreción de procesos de política pública, en los cuales se ven reflejados las percepciones de las personas formuladoras de políticas.

5 Las personas entrevistadas dieron autorización de utilizar sus nombres en el presente artículo, salvo en algunos casos, en los que se hace referencia, con su permiso, solamente a su función institucional. 


\section{TRAS DE CUERNOS PALOS: PERCEPCIONES SOBRE LA INMIGRACIÓN EN LA CCSS}

\section{A) ¿COSTA RICA COMO IMÁN DE BIENESTAR?}

Antes de indagar sobre los efectos de la inmigración nicaragüense en Costa Rica, se preguntó a las personas entrevistadas sobre las razones de la migración y por qué las personas escogen el país como destino. Específicamente, se buscó evaluar las narrativas sobre la política social como factor de atracción y si fuera un factor suficientemente fuerte para explicar la migración hacia Costa Rica. En otras palabras, ¿consideran las y los funcionarios de la DGME $y$ la ccss al país, un imán de bienestar?

Durante las entrevistas, se encontró un abanico de respuestas que se articulan en torno a tres grandes ideas, que reflejan diferentes intensidades del argumento de imán de bienestar. Primero, algunas personas entrevistadas consideran que la política social, específicamente, el acceso a los servicios de salud, puede ser un factor explicativo suficientemente fuerte para entender la migración desde Nicaragua, especialmente de ciertos tipos de población como adultos mayores, mujeres embarazadas $y$ mujeres con hijos e hijas pequeños. Segundo, la política social es considerada un factor secundario en la decisión de migrar, que en sí es una estrategia familiar de bienestar donde inciden muchos otros factores, principalmente, el trabajo. Finalmente, existe una visión enfocada en la atracción de Costa Rica como país democrático y de solidez institucional, que representa un contraste importante con el país de origen.

La percepción de que la política social costarricense en general y los servicios de salud en particular, son en sí una razón suficientemente fuerte para que las personas migren, es compartida por funcionarios de ventanillas de la CCSS y la DGME, quienes aseguran que las personas nicaragüenses aprecian el sistema costarricense de salud y educación. "- $-\mathrm{La}$ Caja Costarricense del Seguro Social con todas sus debilidades $y$ con todas sus fortalezas es una seguridad social muy atractiva" (Gissele Román, enfermera ccss, entrevista, 19 de marzo de 2013). Se tiene la percepción de que esta población inmigrante valora mucho este tipo de servicio, incluso se apela al dicho "ticos no saben lo que tienen" porque "-la salud es cara, $y$ el tico no lo sabe pero el extranjero sí, porque el extranjero vive en otras condiciones en sus países" (Marta Jara, médico general, entrevista, 25 de marzo de 2013). De manera similar, basado en su experiencia, un funcionario de plataforma de servicios de la DGME, explica que "-mucha gente viene aquí por el sistema de la Caja, obviamente nos enorgullece" (Juan Carlos Siles, entrevista, 10 de mayo de 2013), que en su visión hace que el país esté "bien visto" (idem).

Por otra parte, se encontró la percepción de que el régimen de política social, especialmente, la salud y la educación, juegan un papel importante en la decisión de migrar, pero por sí solos no tienen suficiente poder explicativo para los flujos migratorios desde Nicaragua. El argumento de imán de bienestar, en estas percepciones, está presente pero pierde centralidad. Más bien, la migración hacia el país constituye una estrategia familiar más integral en búsqueda de mejores condiciones de vida; es decir, se considera más importante los factores como la facilidad de inserción en el mercado laboral (formal o informal), la cercanía geográfica y la existencia de familiares radicados en el país.

En general, son los funcionarios profesionales (doctores, enfermeras, etc.) que ponen más énfasis en el componente laboral, pero que argumentan que hay una serie de factores secundarios que también entran en juego en la decisión de migrar. Aunque no es el enfoque principal del presente artículo, la educación para generaciones futuras, más que el acceso a la salud directo, es percibida como una fuerte atracción. El Director del Hospital México, el Dr. Douglas Montero, por ejemplo, considera que la primera razón de migrar es la falta de oportunidades laborales en Nicaragua y la mayor probabilidad de encontrarse trabajo remunerado en Costa Rica, pero al mismo tiempo cree que:

-... no es solamente laboral, de hecho, los nicaragüenses no siempre ganan bien y no siempre están en buenas condiciones sociales, algunos trabajan bajo 
condiciones de hacinamiento, mala paga, etc. Pero saben que si tienen una emergencia pueden acceder a los servicios de la Caja, saben que si los hijos empiezan a nacer aquí pueden empezar a tener educación, entonces sacrifican algunos años de estar mal para irse dando la oportunidad de conocer el país (...) Es un tipo de estrategia familiar a largo plazo. Esa gente tiene oportunidad de seguir viviendo en Nicaragua, tienen sus hogares, tienen sus condiciones pero prefieren seguir viviendo aquí por la Caja Costarricense del Seguro Social, por la mejor educación que aquí reciben (Douglas Montero, Director médico del Hospital México, entrevista, 23 de mayo de 2013).

Una posible explicación de esta visión más integral, es que los funcionarios profesionales en salud se relacionan con la población inmigrante más allá de los trámites burocráticos que hacen los funcionarios operativos $y$ por eso posiblemente conocen en mayor detalle las trayectorias de sus pacientes. Una visión similar se sostiene en algunas partes de la DGME, en la Dirección de Integración, aunque no necesariamente en los más altos rangos. Por ejemplo, Cinthia Mora, asesora de esta Dirección, tiene una visión un poco más crítica, argumentando que suponer que en Costa Rica, los servicios de salud son el gran atractivo que impulsa la migración es riesgoso. Para ella:

-... sería un poco osado decir que las ventajas [en beneficios sociales] que presta el país son las únicas que juegan un gol para venir a Costa Rica... sería inclusive caer como en un mito en que más bien no queremos contribuir, porque... ¿Verdad? [El mito] es que vienen $y$ abusan de la Caja (entrevista, 3 de abril de 2013).

Finalmente, en el caso de los funcionarios de más alto rango, el discurso cambia significativamente, aunque su contenido refleja claramente la misma idea de Costa Rica como imán de bienestar. Al encontrarse estas personas en puestos más directamente ligados con la creación y la gestión de políticas, así como, la emisión e implementación de reglamentos y directrices, reflejan una conceptualización más abstracta de la migración (nicaragüense) desde estas lógicas institucionales. Es notable que en esta conceptualización, no se parte de la familia o las estrategias familiares, ni directamente de las características específicas de ciertas poblaciones inmigrantes, como mujeres embarazadas, menores de edad o adultos mayores, o bien de las oportunidades laborales.

En contraste, en este caso se pone más énfasis en la institucionalidad que ofrece el país. Tanto para los más altos funcionarios de la Dirección de Planificación y de Integración de la DGME, así como, la Dirección de Inspección y Área de Coberturas del Estado de la Ccss, la migración en general, pero sobre todo la nicaragüense, es un resultado de la solidez institucional costarricense del país "excepcional" en la región centroamericana. En esta explicación, se menciona la democracia estable como un factor importante. Como lo menciona Eduardo Flores, trabajador de la ccss: "Yo pienso que viene por ahí, cuando a mí me han preguntado otras personas ¿cuál es la diferencia entre Costa Rica y el resto de países de Centroamérica? Yo siempre les he dicho que es que la democracia se ha traducido en el desarrollo institucional del país" (entrevista, 24 de abril de 2013).

El mismo Jefe del Área de Cobertura del Estado de la ccss, menciona que el "desarrollo institucional que tiene el país es un sello de garantía para el migrante y para la gente pobre costarricense de tener buenos servicios en el campo de la salud pública, de la educación, de la vivienda" (entrevista, 24 de abril de 2013). De manera similar, desde la Dirección de Inspección de la ccss se mantiene que:

-... es cierto que estas poblaciones en sus países no tienen las posibilidades ni de tener salud, ni de tener educación, ni de tener agua potable, ni de tener electricidad, ni de tener la institucionalidad de un país, o sea, porque aquí terminamos hablando de institucionalidad... Costa Rica es un país que ha desarrollado la institucionalidad, o sea, hay entes gubernamentales que son los responsables de 
proveer ciertos servicios. Entonces... al final el paquete se vuelve atractivo. Quizás en un momento dado la necesidad trabajo sí, pero la necesidad de trabajo, llega usted y usted empieza a conocer el país donde entro y empieza a ver qué ofrece ese país, y quiere lo que da el país, y reclama lo que da el país (ccss, entrevista, 29 de abril de 2013).

En las tres líneas narrativas, se percibe el régimen de bienestar costarricense como un factor de atracción para la población inmigrante y Costa Rica es considerada un imán de bienestar, aunque haya matices en su centralidad $y$ poder explicativo para los flujos migratorios desde Nicaragua. Parece que el poder explicativo del régimen de política social costarricense es más grande para funcionarios de nivel operativo, se enmarca en una explicación más integral de otros factores, principalmente laborales, para funcionarios profesionales y se diluye hasta cierto punto en las narrativas de los funcionarios de más alto rango, donde la política social en sí no es medular, pero la democracia estable y la institucionalidad costarricense en general, son factores importantes que explican la inmigración.

\section{B) SOBRE CANTIDADES, TIPOS DE INMIGRACIÓN Y EL PROBLEMA DE LA INTEGRACIÓN DEL INMIGRANTE NICARAGÜENSE}

En primera instancia, a las personas entrevistadas se les preguntó sobre su percepción de la cantidad y los tipos de inmigración en Costa Rica. En concordancia con los datos de las Encuestas Nacionales y el Censo (2011), existe la idea generalizada de que la gran mayoría de personas son nicaragüenses. En las entrevistas se mencionaron que otras poblaciones también usan los servicios de la ccss, como los colombianos o bien, estadounidenses y canadienses, pero estas no constituyen la población que más atención demanda. En la DGME y entre funcionarios de alto rango de la ccss se reconoce que hubo un fuerte flujo de migrantes en décadas anteriores pero que ha disminuido en la actualidad.
-Pero este fenómeno de la gran importación de nicaragüenses ya paró, y más bien se está viendo un fenómeno de retroceso, algunos están volviendo y ya como que se estabilizó. Tal vez va disminuyendo lentamente la cantidad de nicaragüenses que están (Douglas Montero, Director médico del Hospital México, entrevista, 23 de mayo de 2013).

Así, por ejemplo, médicos y funcionarios de ventanilla en la ccss estimaron que entre el $50 \%$ o $60 \%$ del total de la demanda de servicios de salud, constituye atención a personas inmigrantes, lo cual les generaba en algunos casos cierto nivel de consternación sobre qué tan justo consideran el hecho de que "acaparen" los servicios de salud. Por otra parte, se observa que existe una cierta preocupación generalizada, no solo en cuanto a la cantidad de nicaragüenses en el país, sino en cuanto al tipo de inmigrante que llega al país. Esta preocupación radica en la consideración de que hay -o hubo- muchos migrantes con ciertas características $y$ patrones culturales cuya inserción en la sociedad costarricense representan un problema. Una constante en las entrevistas era la caracterización de las personas inmigrantes nicaragüenses, como: personas trabajadoras (principalmente en el sector construcción, agrícola, servicio doméstico y comercios informales), de escasos recursos y con un nivel educativo bajo que en general, buscan mejorar su calidad de vida.

La resistencia a la inmigración, en este sentido, no radica en el fenómeno migratorio per se, pero sí a su manifestación en una migración nicaragüense de baja calificación y los problemas de su inserción en la sociedad costarricense; es decir, el inconveniente no es con todo tipo de migrante, sino específicamente con el migrante nicaragüense, el trabajador nicaragüense. A diferencia de los trabajadores que migran directamente contratados por grandes empresas que son trabajadores estables, con domicilio fijo, "-de aquí para allá muchos viven en tugurios, (...) hay lugares donde nosotros mismos no podemos entrar, donde la ambulancia no puede entrar 
porque son lugares que son tomados por los extranjeros, y nosotros lo estamos permitiendo" (Ventanilla empresarial DGME, entrevista, 10 de mayo de 2013).

La Dirección de Inspección de la ccss se refirió a la caída en la actividad de algunos sectores productivos, que hace más difícil la integración de la población inmigrante en general y la nicaragüense en particular, quienes si no encuentran trabajo: "-quedan flotando en el país porque si la actividad económica decae entonces se quedan sin trabajar" (Dirección de Inspección ccss, entrevista, 29 de abril de 2013).

Eduardo Flores, Jefe del Área de Cobertura del Estado de la ccss, hizo una reflexión interesante que apunta al problema intergeneracional de integración que ha generado la inmigración nicaragüense y que el país no ha podido enfrentar con éxito porque: "—no tiene experiencia en [su] manejo... y sí, sí puede convertirse en un problema grave desde el punto de vista socioeconómico" (entrevista, 24 de abril de 2013). Flores infiere que:

-... el desarrollo de las ventas callejeras, los taxis piratas, aperturas de comidas informales $y$, quién sabe, pero en la de menos hasta el mismo negocio de la prostitución y la drogadicción está en manos de esta generación, porque es un grupo de personas que ni completó su educación básica, no se sienten bien con saber que sus padres no nacieron aquí, conservan un orgullo de que nacieron aquí pero que por las condiciones de pobreza en que se desarrollaron no encontraron la llave del progreso que el resto de costarricenses de esa generación se han encontrado" (entrevista, 24 de abril de 2013).

Este "problema de integración" es mencionado como factor que amerite la regulación de los flujos migratorios. Adrián Jiménez, Subjefe de la Dirección de Planificación Institucional de DGME, explicó que:

-... cuando se establecen límites es por el tipo de personas que nosotros queremos que vengan, porque aunque suene muy feo, Costa Rica no puede ser un importador de pobreza, tenemos que salir también de problemas económicos y sociales del país, que no podemos importar una serie de factores endógenos que nos vienen a hacer la situación más crítica (entrevista, $1^{\circ}$ de abril de 2013).

En general, funcionarios de diversos rangos en la cCSS y DGME perciben la inmigración nicaragüense, más que de otras nacionalidades, como una amenaza, bajo la constatación que son principalmente inmigrantes de bajo estrato socioeconómico. Muchos consideran que con el crecimiento de esta población, esto podría provocar problemas en la demanda de servicios públicos. Por esta razón y la correlación explícita que expresaron entre esta inmigración y muchas problemáticas sociales en Costa Rica, se convierten en principales argumentos para la regulación de los flujos migratorios.

Segundo, la política migratoria costarricense se ha abierto a los conceptos de integración y a los derechos humanos como se aprecia en las entrevistas con altos rangos dentro de la ccss, ya que hubo consciencia de estos derechos de las personas inmigrantes; por lo tanto, en general se conceptualiza una vinculación de estos derechos con el estado migratorio. En otras palabras, existe el discurso de que son muchos los inmigrantes pero que tienen derecho igual que los nacionales, siempre y cuando estén en condición legal regular y que cumplan con sus deberes, en el caso de la salud, el aseguramiento y la cotización a la ccss. Siguiendo a Domenech (2011), la línea divisoria en el discurso de los funcionarios de instituciones públicas se centra en la dicotomía legal-ilegal, estado que define el aporte al país. Esto delimita la legitimidad percibida de la demanda de servicios de salud que tiene la población inmigrante nicaragüense.

\section{C) LA LEGALIDAD COMO BASE PARA UNA DEMANDA LEGÍTIMA DE SERVICIOS DE SALUD}

En general, la demanda de servicios sociales y en este caso, la salud se percibe como legítima si la persona inmigrante se encuentra en condición migratoria "legal", siempre 
y cuando "aporte" al país y al Seguro Social. Es notable que los derechos humanos, en los cuales la política migratoria actual se inspira según los funcionarios de la DGME y confirmado por estudios académicos (Kron, 2011 y López, 2012), no tiene la misma centralidad que el estado legal de la persona inmigrante y los beneficios que podría implicar su estadía al país.

Cuando se preguntó sobre la protección de ciertas poblaciones inmigrantes, como mujeres embarazadas, menores de edad y adultos mayores entre otras categorías, que en caso de no encontrarse aseguradas, cuentan con una cobertura del Estado sin costo alguno, un funcionario de plataforma de servicios de la DGME expresó que "-el error [que Costa Rica ha cometido] es que nosotros firmamos todo lo que nos pongan adelante por los derechos humanos, sin pensar qué nos va a traer, si nos va a dar beneficios, o si no nos va a beneficiar" (ventanilla empresarial, entrevista, 10 de mayo de 2013).

Esa idea de que la inmigración tiene que traer un beneficio al país se encuentra en las percepciones de muchas personas entrevistadas, sin importar el rango. Por ejemplo, tanto con la Dirección de Planificación como de Integración de la DGME, se reconoce por un lado, los derechos de las personas inmigrantes, pero al mismo tiempo, se hace mucho énfasis en sus deberes. Estos deberes son principalmente el conseguir un estado migratorio regular y contribuir al sistema del Seguro Social de la ccss, aunque desde la Ley nro. 8764, estos dos deberes son implícitamente lo mismo (Voorend, 2013).

En la entrevista con el Director de Integración, Julio Aragón y el Subjefe de Planificación Institucional, Adrián Jiménez, ambos de la DGME, las demandas de servicios de la población inmigrante en sí no representan un problema, mientras cumplan con sus deberes. Por ejemplo, Adrián Jiménez menciona que no se debe llegar a exigir sin antes cumplir con los deberes:

-Ahora si usted llega y me dice —es que yo quiero esto $y$ me lo tiene que dar ya, bueno un momento, usted sabía que usted no viene solo a pedir, usted también tiene deberes ¿qué paso con esto?- Ay no. ¡Ah ok! entonces cúmplame usted primero con eso y yo le doy esto. Entonces, también hay que hacerle ver a la gente que no es nada más una cuestión de derechos, es también una cuestión de deberes, entonces las instituciones se acomodan mejor (Subjefe de Planificación Institucional DGME, $1^{\circ}$ de abril de 2013).

En la ccss se maneja una posición similar. Como lo expresó un funcionario de la Dirección de Inspección de esta institución, el migrante puede venir:

-... mientras esté aquí haga las cosas bien y con mucho gusto, porque él se puede ir pero puede venir otro $y$ encuentra un sistema que lo reciba verdad, esa es la gran lucha, $y$ todo este tema yo creo que a la sociedad costarricense nos ha cambiado porque se creía que la Caja, la gente tenía la percepción Caja-gratuidad (cCss, entrevista, 29 de abril de 2013).

En la misma línea, el Director del Hospital México se preocupaba por la inmigración nicaragüense y "-que eso podría llevar a contraste no solo a la Caja sino al país, porque era una serie de personas que utilizaban los servicios costarricenses pero no estaban aportando, $y$ en el caso de la Caja es sumamente grave, extrae mucho recurso y no estaba dando nada" (Douglas Montero, entrevista, 23 de mayo de 2013), aunque él percibe que se ha podido controlar mejor la situación en los últimos años: "la cantidad de nicaragüenses que están ahora, que se han quedado más en el país, ya están contribuyendo (...) sí sigue impactando, y sí sigue afectando nuestros recursos pero ya no pone en riesgo la institución”(idem).

Bajo preocupaciones similares sobre la contribución de la población inmigrante al país en general y la ccss en particular, por un lado, los funcionarios de la DGME dan centralidad al estado migratorio regular como la condición para legitimar su demanda a los servicios del Estado, mientras por otro lado, los funcionarios de la ccss (por lo menos de los rangos altos) dan mucha importancia a la contribución al 
seguro social. En este momento, la Ley de Migración establece el seguro social como requisito a un estado migratorio regular, mientras que la CCSS, siguiendo una solicitud de la DGME, estableció el estado migratorio regular como requisito para el aseguramiento (Voorend, 2013). Así, para funcionarios de ambas instituciones, la demanda de inmigrantes de servicios de salud es legítima, siempre y cuando estén en condiciones "legales" y "contribuyan" a estos servicios.

En este sentido, los derechos sociales se vinculan directamente con la dicotomía "legalilegal" y la regularización se vuelve central en la política migratoria, de la cual la ccss forma una parte integral desde el 2009 (Voorend, 2013). La ilegalidad se convierte en un costo para la institución, bajo la lógica de que la persona inmigrante "ilegal" no es un contribuyente, así que al hacer uso de los servicios de salud, lo que queda es una factura pendiente de cobro a cargo del Estado. Al respecto, Jiménez sostiene que "—no se le puede negar la atención a nadie, pero si no está asegurado tome, aquí está la factura o sea, hay que ser solidario pero no tonto porque si no la Caja quiebra" (Subjefe Planificación, DGME, entrevista, $1^{\circ}$ de abril de 2013).

Es notable esta visión, pues refleja ciertas contradicciones, dado que estudios de la misma DGME han demostrado que el inmigrante no representa una carga para el sistema del Seguro Social (DGME, 2011) y dentro de las entrevistas, los mismos funcionarios hicieron referencia a dicho estudio; asimismo, se observa la tensión existente entre el imaginario del inmigrante $y$ la construcción de la otredad, en donde los problemas de la Caja se atribuyen a las personas inmigrantes.

Las entrevistas sugirieron que incluso, a niveles altos de la DGME y la ccss, se considera la inmigración como un reto importante para la sostenibilidad financiera del régimen de política social costarricense; no obstante, algunos estudios publicados por sus propias instituciones demuestran lo contrario, a pesar del reconocimiento de los derechos humanos de la persona inmigrante, que se destaca tanto en el marco institucional como en las entrevistas. De ahí se desprende la importancia que ha tenido la "legalidad", entendida como el estado migratorio regular y el aseguramiento por parte de la ccss, temas que se reflejan también ampliamente, en la Ley de Migración nro. 8764.

Para funcionarios en rangos operativos, e incluso para funcionarios profesionales de la CCSS y la DGME, la narrativa cambia significativamente $y$ refleja una preocupación aún más grande por la sostenibilidad de la ccss, cuestionando mayormente el derecho a la salud de la población inmigrante. Específicamente, consideran que el conocimiento del derecho a la salud por parte de la población inmigrante y la cobertura que da el Estado, en caso de que no se pueda pagar los servicios de salud a través del Seguro por el Estado, son factores que afectan seriamente a la ccss. Dado que "-el Estado les paga esto, entonces, quizá por esa parte sí nos afecta la parte económica" (trabajadora de ventanilla, ccss, entrevista, 25 de marzo de 2013). En este contexto, la demanda de servicios de salud por parte de inmigrantes tiene una connotación negativa:

—... ha afectado digamos la economía, la situación de la Caja, por todo eso, los beneficios que se les da a la población que cubre el Estado. Se nos vienen en situaciones, se podría decir derechos que tiene esa población. Están cubiertos por leyes, leyes especiales. Entonces eso si nos afecta ¿a quién se le cobra? (idem).

Entre funcionarios operativos se observa una constante preocupación por la manera en que financieramente, la Caja enfrenta estas situaciones, porque tal como menciona Marta Jara, Médico General de la ccss, la comunidad nicaragüense está consciente de que es de carácter obligatorio atender niños y mujeres embarazadas. Hay quienes se preocupan de que el brindar estos servicios a esta población afecte a la ccss: "- -si llena los requisitos, es porque no se le puede negar. Entonces sí afecta y sí vemos que el bolsillo de la Caja está siendo afectado" (Giselle Román, enfermera ccss, entrevista, 19 de marzo de 2013).

Otra preocupación importante no gira alrededor de la sostenibilidad financiera, pero 
refleja el temor de una saturación del sistema. Por ejemplo, un funcionario de ventanilla preferencial, más allá de preocuparse por el impacto que tiene el Seguro por el Estado, considera que al brindar tantos servicios a las personas inmigrantes "-le estamos quitando a los costarricenses" (Juan Carlos Siles, ccss, entrevista, 10 de mayo de 2013).

Esta preocupación expresada especialmente por funcionarios operativos, transciende la diferenciación legal-ilegal que forma la base para la preocupación financiera. Se observa que hay quienes independientemente de si la persona extranjera es cotizante o no, la demanda de servicios de la Caja por parte de esta persona, afecta a los costarricenses por una saturación del sistema de servicios de salud. Giselle Román, funcionaria del área de salud, por ejemplo, sostiene que "-resulta que estamos sobrepoblados de extranjeros, entonces gente que, vuelvo a lo mismo, requiere la atención en seguridad social y se le está brindando" (entrevista, 19 de marzo de 2013). En las narrativas destaca la idea de sobrepoblación y se habla de "extranjeros" (en general), no necesariamente de una persona inmigrante "ilegal".

El cuestionamiento del derecho a la salud, en este caso, va más allá del tema de legalidad o de aseguramiento, e implica directamente la exclusividad (deseada) de los beneficios de bienestar para nacionales. Esta percepción posiblemente se fundamenta en la menor capacidad del Estado de ofrecer protección a sus ciudadanos y de la ccss de brindar los servicios de salud necesarios (Martínez, 2008a; Martínez y Sánchez-Ancochea, 2013).Al mismo tiempo, presenta una controversia seria sobre la legitimidad de la demanda de servicios de salud por parte de la población inmigrante.

Se argumenta que este tipo de controversias están basadas en directrices como la emitida por el Jefe del Departamento de Cobertura del Estado de la ccss. Incluso, se ve reflejado en la Ley de Migración nro. 8764 del 2009, que en términos prácticos crea una situación legal en que el estado migratorio regular depende del seguro social de la ccss y viceversa, lo que refuerza la idea del inmigrante "ilegal" que no contribuye al sistema de salud. Además, como reacción a la crisis en la ccss y en combinación con la DGME, se fortalece la lógica contributiva de la Caja y del sistema solidario que da soporte al "universalismo" costarricense, al establecer por ejemplo, no solo la regularización como requisito para el aseguramiento directo, pero también de todos los familiares mayores de edad para el seguro familiar indirecto.

Con esto, la política migratoria costarricense apunta a una política de regularización de los flujos migratorios, que -aunque existen cuestionamientos sobre su efectividad (Sandoval, inédito y Voorend, 2013) - por un lado, propone una solución a la cuestión de ilegitimidad de demanda de servicios de salud, pero al mismo tiempo, crea "fronteras en torno a cuestiones de distribución de los recursos del estado de bienestar" (Voorend, 2013: 7).

\section{D) SOBRE LA LEY DE MIGRACIÓN Y EL ENDURECIMIENTO DE LA CCSS}

En términos generales, la Ley nro. 8764 es percibida como un instrumento que incide en la construcción de una cultura de solidaridad, de crear conciencia sobre los deberes de la población inmigrante $y$ principalmente, sobre la importancia de su documentación. Un funcionario de la Dirección de Inspección de la ccss sostiene que era necesario, dado que:

—... les falta esta sensibilidad hacia la solidaridad y la importancia de contribuir, o sea ellos no tienen esa cultura entonces hay que construir esa cultura. O sea, yo no creo que sea solo un tema de yo critico al inmigrante que viene $y$ no quiere cotizar, o al inmigrante critica al nacional que no le ve bien, no, este es un tema que más de fondo ¿cómo construimos una cultura de contribución? (ccss, entrevista, 29 de abril de 2013).

Aunque algunos estudios han criticado los altos costos que implica el proceso de regularización propuesto por la Ley (IIS et ál., 2012; Voorend, 2013; Sandoval, inédito), para los funcionarios de alto rango en la DGME, el principal problema no es económico, sino de concientización. La Ley contribuye a este proceso de 
concientizar a la población inmigrante de que es preciso regular y contribuir a la ccss, por lo cual las familias deben priorizar el cumplimiento de dicha obligación por encima de otros gastos. Julio Aragón, Dirección de Integración de la DGME, explica que con la Ley logran "-incidir, por poner ejemplos entre varios, que en vez de la antena parabólica la de Claro o Direct TV verdad, la prioridad tuvo que haber sido regularizar a alguno de los miembros y después la antena" (entrevista, $1^{\circ}$ de abril de 2013).

Asimismo, se acuerda que la Ley ayuda a crear la reciprocidad necesaria para que se perciba la demanda de servicios de salud por parte de inmigrantes (nicaragüenses) como legítima: "-nosotros somos solidarios recibiendo a los inmigrantes, pero los inmigrantes tienen que ser solidarios con el país a dónde llegan" (Dirección de Inspección, ccss, entrevista, 29 de abril de 2013). En este caso, ser solidario con el país, implica regularizarse y contribuir a la ccss a través del Seguro Social. La Ley parece ser la percepción generalizada, funciona como una herramienta que ayuda en el proceso de regularización y así crea la solidaridad, aunque no de manera voluntaria. Así, la Ley es percibida positivamente pues viene a ordenar los flujos migratorios y beneficia a la ccss con más contribuyentes.

Según Julio Aragón de DGME, contar con más contribuyentes es primordial para la ccss, dado el contexto del 2011, cuando salió a la luz la crisis de sostenibilidad financiera de esta institución. La Ley le ayuda a la ccss a defender:

-... su visión de costos versus su visión humanitaria, ¿verdad? Migración [DGME] lo que ha establecido es que esto ha sido positivo para la misma Caja como empresa ¿por qué? Porque puso en orden $y$ le dio la ruta de que el grueso de las personas que utilizan los servicios de la Caja realmente aporten a esa empresa como tal, entonces esa es la parte positiva (entrevista, $1^{\circ}$ de abril de 2013).

Por otra parte, tanto funcionarios de la DGME como de la ccss hacen hincapié en que los cambios en la Ley y el endurecimiento de las reglas de la ccss, responden a una cuestión de orden y no constituyen ninguna forma de discriminación: "- -el país (...) cada vez tiene que ordenarse más, entonces hay que ubicar cosas en su verdadero contexto. $\mathrm{O}$ sea, a mí no me tratan mal si me exigen documentos ¡Por Dios es lógico que yo tenga documentos!" (funcionario de la Dirección de Inspección, ccss, entrevista, 29 de abril de 2013). Al mismo tiempo, varias personas entrevistadas hicieron mención de que la ccss, en el contexto de la crisis, "también se ha vuelto más estricta" incluso, "más agresiva" (Dirección de Inspección, 29 de abril de 2013).

Este "endurecimiento" de las políticas institucionales implica en la práctica, por un lado, la regularización como requisito para el aseguramiento $y$ por otro lado, que ya no se atienden pacientes sin documentación y sin seguro, salvo por emergencia, en cuyo caso se cobra por los servicios. Esta segunda política ya existía, aunque no fue aplicada estrictamente antes del 2011 (Voorend, 2013).

Esta tendencia dentro de la ccss no es cuestionada en mayor medida por los funcionarios de la Institución, independientemente del rango que ocupan dentro de ella $y$ se considera en general, como algo positivo, bajo el argumento de reciprocidad mencionado, pero también, bajo un argumento técnico. Los funcionarios, tanto de alto rango como los profesionales, apelan a que los documentos de identificación y el registro en el sistema del Seguro Social, son vitales en los servicios de salud, dado que sin poder corroborar la identificación, no se puede atender a una persona sin poner en riesgo su salud.

Más allá del aspecto financiero, algunas personas entrevistadas mencionaron los beneficios que tiene la Ley de Migración en combinación con las políticas de la ccss, para la población inmigrante beneficiaria de los servicios de salud. Por ejemplo, para la Dra. Ana Patricia Salas, de la Contraloría de Servicios de la ccss, los cambios de la Ley no constituyen un endurecimiento en el control migratorio ni de las reglas de la ccss, pero es una medida que beneficia directamente a las y los inmigrantes:

-Pues yo creo que más bien les ayuda, les ayuda en ese sentido porque ya ellos 
con documentos $y$ todo pueden accesar los servicios en cualquier momento. No que se veía que una parte de esta población iba a emergencias en las noches cuando no había ya control de validación de derechos, en cambio ya ellos regular, su seguro, aparte como les digo la ventaja de que la cotización les está corriendo por una pensión futura y tal vez había gente que tenía diez-quince y jamás los habían asegurado (Contraloría de Servicios, Ccss, entrevista, 22 de abril de 2013).

En general, la Ley es percibida como una herramienta que ayude a solucionar el problema de la irregularidad de una buena parte de la población inmigrante, principalmente nicaragüense. Poniendo presión sobre esta población, la Ley "concientiza" sobre los deberes y ayuda a crear una cultura de "solidaridad" y de "reciprocidad", la cual es poco cuestionada por las dificultades que crea para la población inmigrante de acceder los procedimientos burocráticos de la regularización o bien, los altos costos que estos implican (IIS et ál., 2012; Voorend, 2013 y Sandoval, inédito).

\section{CONCLUSIONES}

En este artículo se analizaron las narrativas de una muestra de funcionarios de diferentes rangos de la CCSS y de la DGME, instituciones que juegan un papel clave en la política migratoria costarricense actual (Voorend, 2013). Se argumenta que es importante analizar estas narrativas porque inciden en la formación de políticas públicas y su ejecución diaria (Dobles, Vargas y Amador, 2014). Este análisis se centra en la idea de Costa Rica como imán de bienestar, la legitimidad de la demanda de servicios de salud por parte de la población inmigrante nicaragüense y la percepción sobre la reforma de Ley de Migración nro. 8764 (2009).

En las entrevistas, se encontró una constante, aunque funcionarios de diferentes rangos lo formulan de manera distinta y le dan mayor o menor centralidad en su explicación del país como atractivo para personas inmigrantes: Costa Rica es entendida como un imán de bienestar. La política social en general, pero especialmente, la salud a corto y mediano plazo, así como, el acceso a la educación a futuro (para los hijos e hijas), son en las percepciones de los funcionarios, fuertes factores explicativos de la migración nicaragüense hacia Costa Rica.

Sin embargo, por las características específicas de esta migración, pero sobre todo porque el inmigrante es percibido como una amenaza y la inmigración nicaragüense como un "mal necesario" (Dobles, Vargas y Amador, 2014). Además, existe la constante percepción de que la mayoría de ellos entra al país en condiciones irregulares (Sandoval, 2008), lo cual conlleva a que su demanda de servicios de salud no es considerada legítima en muchos casos. Esta legitimidad gira alrededor de la cuestión de la "legalidad" de la persona, aunque existen estudios que demuestran que se trata más de una percepción de su estado migratorio que la regularidad en sí, dado que "los políticos y los proveedores de servicios tienden a ignorar las diferencias entre (...) migrantes [regulares] $y$ otras categorías migratorias (como inmigrantes "ilegales") y (...) niegan beneficios a todos los migrantes independientemente de su condición” (López, 2012: iv).

La actual política migratoria costarricense apunta a esta legalidad, dándole centralidad al asunto de la regularización. Existe una tensión entre el reconocimiento de derechos humanos y la restricción en el acceso a beneficios de bienestar. Esta tensión se resuelve con la justificación de la ilegalidad: una persona inmigrante considerada como "ilegal" es carente de derechos sociales y por eso, la política migratoria tiene que apuntar a ordenar $y$ regularizar los flujos migratorios. Así, las entrevistas, especialmente con funcionarios de alto rango, reflejan que "la ilegalidad estructura la visión de Estado" (idem, cursiva en original).

En las entrevistas, los derechos sociales son una función no solo del estado migratorio regular, pero también de la "solidaridad" que demuestran las y los inmigrantes con el aseguramiento con la ccss. En la percepción de funcionarios de alto rango, un limitante importante con la inmigración nicaragüense es que no tienen la "cultura" de contribuir al Seguro Social y entienden erróneamente que hay un principio de "gratuidad" en la prestación 
de servicios en Costa Rica. Así, no solo es la inmigración "construida como problema fundamentalmente a partir de la ilegalidad que se le adscribe" (Domenech, 2011: 33), sino del aporte que hace la inmigración a la sostenibilidad de las instituciones públicas sociales.

Combinado con la coyuntura actual de crisis de la ccss, institución emblemática del régimen de protección social costarricense, esto ha creado tierra fértil para crear restricciones al acceso a los servicios de salud (Voorend, 2013) para poblaciones inmigrantes que no "aportan", entendido el aporte como el aseguramiento directo en un estado legal.

Es esta crisis de la cCSS en particular, sumado a los discursos de otredad (Sandoval, 2008), terminan generando la sensación de "tras de palos, cuernos"; es decir, tras de que estamos mal, tenemos que aguantarlos a los inmigrantes nicaragüenses. Esta sensación parece haber incentivado un endurecimiento de las políticas institucionales de la ccss, usando la Ley nro. 8764 como herramienta para su efectuación, en cercana colaboración con la DGME. Así, el Seguro Social de la ccss en particular, se ha convertido en pilar central de la política migratoria costarricense.

En general, parece que este tipo de percepciones y narrativas juegan un papel importante en la formación de políticas, específicamente en la Reforma de la Ley nro. 8764 $y$ el endurecimiento de la ccss, a pesar de que investigaciones académicas $y$ datos duros han demostrado que el inmigrante aporta más de lo que "usa" de la cCSS (DGME, 2011), que no fue causante de la crisis de esta institución (DGME, 2011 y oPs, 2011) y que no está sobrerrepresentado como pacientes en los servicios de salud (Castillo, 2003), salvo en algunos casos por su situación socio-económico y no por la dimensión migrante.

En este sentido, es preocupante la directriz emitida por la cCSs, donde se cuestiona el derecho a servicios a la salud pre-natal, un derecho históricamente universal en Costa Rica. Aunque fue cancelada por la misma institución con base en las leyes que protegen al niño (no nacido), porque una mujer embarazada en Costa Rica "vale más que la reserva del Banco
Central", es alarmante que dentro de la misma ccss, institución emblemática del universalismo costarricense, se manifiesta que "-si no está en urgencia jálese, piérdase de aquí, yo no tengo por qué atender la paciente que no está en urgencia" (Eduardo Flores, Jefe Departamento Cobertura del Estado, ccss, entrevista, 24 de abril de 2013).

Efectivamente, la política social se ejecuta en la "ventanilla", pero en el décimo piso, donde se crea la política, se encuentra una misma tensión entre el compromiso de brindar servicios considerados un derecho humano y el deseo de negar atención médica para los pacientes que no "merecen" estos servicios.

\section{BIBLIOGRAFÍA}

Acuña, G.; Herra, E. y Voorend, K. Flujos migratorios intrarregionales: situación actual, retos y oportunidades en Centroamérica y República DominicanaInforme de Nicaragua. San José, Costa Rica: Organización Internacional para las Migraciones-oim, Organización Internacional del Trabajo-oIT, Coordinación Educativa y Cultural Centroamericana del Sistema de la Integración Centroamericana - CECC SICA, Red de Observatorios Regionales del Mercado de Trabajo-ORMET, 2013.

Banting, K. "Looking in three directions: migration and the European welfare state in comparative perspective". Immigration and welfare. Challenging the borders of the welfare state. $\mathrm{M}$. Bommes y A. Geddes (eds.). Londres, Inglaterra y New York, EEUU: Routledge, 2000.

Bauböck, R. Transnational citizenship. Membership and rights in international migration. Aldershot, Inglaterra: Edward Elgar Publishing Limited, 1995.

Baumeister, E.; Fernández, E. y Acuña, G. Estudio sobre las migraciones regionales de los nicaragüenses. Ciudad de Guatemala, Guatemala: Editorial de Ciencias Sociales, 2008.

Boeri, T.; Hanson, G. y McCormick, B. (eds.). Immigration policy and the welfare 
system. Oxford, Inglaterra: Oxford University Press, 2002.

Bonilla-Carrión, R. "Seguro social y usos de servicios de salud entre personas nicaragüenses en Costa Rica". El mito roto. Inmigración y emigración en Costa Rica. Carlos Sandoval (ed.). San José, Costa Rica: Editorial de la Universidad de Costa Rica-EucR, 2007.

Borjas, George J. "Immigration and welfare 1970-1990”. Working Paper 4872. Cambridge, Inglaterra: National Bureau of Economic Research, 1994.

Borjas, George J. "Immigration and welfare magnets". Working Paper 6813. Cambridge, Inglaterra: National Bureau of Economic Research, 1998.

Borjas, George J. "Immigration and welfare magnets". Journal of labor economics 4 (17). Chicago, Eeuu. The University of Chicago Press, 1999: 607-637.

Borjas, George J. "Welfare reform, labor supply, and health insurance in the immigrant population". Journal of Health Economics 6 (22). Elsevier. Noviembre 2003: 933-958.

Borjas, George J. y Hilton, Lynette. "Immigration and the welfare state: immigrant participation in means-tested entitlement programs". The Quarterly Journal of Economics 2 (111). Oxford, Inglaterra. Oxford Journals, mayo 1996: 575-604.

Bourdieu, P. Cuestiones de Sociología. Madrid, España: Istmo, 2000.

Bravo, J. "Inmigrantes aportan a la seguridad social costarricense". La Prensa. Managua, Nicaragua. 2009. En: <http:// www.laprensa.com.ni/2009/12/14/ economia/10369> [consultado el 08 de octubre de 2012].

Caja Costarricense de Seguro Social (ccss). "Afiliación y prestación de servicios de salud a los asegurados extranjeros no habilitados legalmente para trabajar en el país". Comunicación interna. San José, Costa Rica: ccss, 10 de abril de 2012.

Caja Costarricense de Seguro Social (ccss). "Recordatorio sobre disposiciones vigentes para el trámite de verificación, validación y facturación de servicios médicos en los centros de salud de la Caja”. Comunicación interna. San José, Costa Rica: ccss, 21 de junio de 2012.

Carrillo Lara, R.; Martínez Franzoni, J.; Naranjo Villalobos, F. y Sauma Fiatt, P. Informe del equipo de especialistas nacionales nombrado para el análisis de la situación del seguro de salud de la CCSS. Recomendaciones para restablecer la sostenibilidad financiera del seguro de salud. San José, Costa Rica: ccss, 2011.

Castillo, J. Características de la Atención de los Extranjeros en los Servicios de Salud de la Caja Costarricense de Seguro Social 1997-2002. Presidencia Ejecutiva, Dirección Actuarial y de Planificación Económica. San José: ccss, 2003.

Danson, M.; McAlpine, R.; Spicker, P. y Sullivan, W. The case for universalism. An assessment of the evidence on the effectiveness and efficiency of the universal welfare state. Biggar: The Jimmy Read Foundation, 2012.

De Jong, Gordon y Graefe, Deborah. "Welfare reform and migration: moving to benefits; moving from restrictions". Reporte. Northwestern University/ University of Chicago Joint Center for Poverty Research. Pennsylvania, EEuU: The Pennsylvania State UniversityPopulation Research Institute, 2002.

Dirección General de Migración y Extranjería de Costa Rica (DGME). "Migración e integración". Primer Reporte Anual. San José, Costa Rica: DGME, 2011.

Dobles, I.; Vargas, G. y Amador, K. Inmigración: Psicología, identidades y políticas públicas. La experiencia nicaragüense y colombiana en Costa Rica. San José: Editorial de la Universidad de Costa Rica, 2014.

Domenech, E. "Crónica de una 'amenaza' anunciada. Inmigración e 'ilegalidad': visiones de Estado en la Argentina contemporánea". La Construcción del sujeto migrante en América Latina: Prácticas, representaciones y categorías. 
Feldman-Bianco, B.; Rivera, L.; Stefoni, C. y Villa, M.I. (eds.). Quito, Ecuador: FLACSO-CLACSO-Universidad Alberto Hurtado, 2011.

Easterly, William y Levine, Ross. "Africa's growth tragedy: policies and ethnic divisions". The Quarterly Journal of Economics 112. Oxford, Inglaterra. Oxford Journals. 1997: 1203-1250.

Faist, Thomas. "Immigration, integration and the ethnicization of politics". European Journal of Political Research 25. Alemania, 1994: 439-459.

Faist, Thomas. "Immigration, integration and the welfare state". The challenge of diversity integration and pluralism in societies of immigration. A. Heller, R. Bauböck y A.R. Zolberg (eds.). Aldershot, Inglaterra. Avebury, 1996: 227-250.

Feldman-Bianco, B.; Rivera, L.; Stefoni, C. y Villa, M.I. (comps.). La construcción social del sujeto migrante en América Latina. Prácticas, representaciones y categorías. Quito, Ecuador: FLACSO-CLACSOUniversidad Alberto Hurtado, 2011.

Fischer, A. "Towards genuine universalism within contemporary development policy". High level policy forum-after 2015: promoting pro-poor policy after the MDGS. Bruselas, Bélgica. 2009.

Freeman, G. "Migration and the political economy of the welfare state". The Annals of the American Academy of Political and Social Science 485. Pennsylvania, EEUU. University of Pennsylvania, 1986: 51-63.

Hollifield, J.F. "Immigration and the politics of rights. The French case in comparative perspective". Immigration and welfare. Challenging the borders of the welfare state. M. Bommes y A. Geddes (eds.). Londres, Inglaterra y New York, EEUU: Routledge, 2000.

Hujo, K. y Piper, N. "Linking migration, social development and policy the South". South-South migration. Implications for social policy and development. K. Hujo y N. Piper (eds.). Hampshire, Inglaterra: Palgrave Macmillan-The
United Nations Research Institute for Social Development (UNRISD), 2010.

Instituto de Investigaciones Sociales-IIS; Centro de Investigación en Cultura y Desarrollo; Programa Radiofónico Casa Abierta 870 UCR; Servicio Jesuita para Migrantes Costa Rica. "La Ley de Migración en Costa Rica: A dos años de su entrada en vigencia. Promesas, realidades y desafíos, 2012". Conferencia de Prensa. 2012. En: http://www.lanuevaprensacr.com/la-leyde-migracionen-costa-rica-a-dos-anosde-su-entrada-en-vigencia-promesasrealidades-y-des [consultado el 16 de abril de 2013].

Instituto Nacional de Estadística y Censos de Costa Rica (INEC). Censo de población 2011. San José, Costa Rica, 2011.

James, E. "Why do different countries choose a different public/private mix of educational services?". Journal of Human Resources 3(28). Wisconsin, Eeuu. University of Wisconsin Press, 1993: 531-592.

Kofman, E.; Phizacklea, A.; Raghuram, P. y Sales, R. Gender and international migration in Europe. Employment, welfare and politics. Londres, Inglaterra y New York, EEUu: Routledge, 2000.

Korpi, W. "Social policy and distributional conflict in the capitalist democracies: a preliminary comparative framework". West European Politics 3 (3). Londres, Inglaterra. 1980: 296-316.

Kron, S. "Gestión migratoria en Norte y Centroamérica: manifestaciones y contestaciones". Anuario de Estudios Centroamericanos 37 (53-85). San José, Costa Rica. Universidad de Costa Rica, 2011: 53-85.

Lister, R. The exclusive society: citizenship and the poor. Londres, Inglaterra: Child Poverty Action Group, 1990.

López Ruiz, M. "The incorporation of Nicaraguan temporary migrants into Costa Rica's healthcare system: an opportunity for social equity". [Tesis de doctorado]. Canadá: University of Windsor, 2012. 
Martínez Franzoni, J. Domesticar la incertidumbre en América Latina: mercados laborales, politica social y familias. San José, Costa Rica: Editorial de la Universidad de Costa Rica, 2008a.

Martínez Franzoni, J. ¿Arañando bienestar? Trabajo remunerado, protección social y familias en América Central. Buenos Aires, Argentina: Consejo Latinoamericano de Ciencias Sociales-CLACSO, 2008b.

Martínez Franzoni, J. y Sánchez-Ancochea, D. "Inroads towards universalism: how Costa Rica informs theory". Documentos de trabajo. Notre Dame, Francia: Kellogg Institute for International Studies, 2012.

Martínez Franzoni, J. y Sánchez-Ancochea, D. Good jobs and social services: how Costa Rica achieved the elusive double incorporation. United Kingdom: Palgrave, 2013.

McCarty, T. "Demographic diversity and the size of the public sector". KYKLOS 46 (2). New Jersey, Eeuu. Wiley-Blackwell, 1993: 225-240.

Mkandawire, T. "Targeting and universalism in poverty reduction. Social Policy and Development Programme". Paper 23. Geneva: UNRISD, 2005.

Morales, A. y Castro, C. Migración, empleo y pobreza. San José: Flacso-Costa Rica, 2006.

Muenz, R. y Fassmann, H. Migrants in Europe and their economic position: evidence from the European Labour Force Survey and from other sources. Hamburg: Hamburg Institute of International Economics-HWWA, 2004.

Noy, S. "World bank projects and targeting in the health sector in Argentina, Costa Rica and Peru, 1980-2005". International Sociological Association-ISA Forum. Buenos Aires, Argentina. $1^{\circ}$ al 04 de agosto de 2012.

Organización Panamericana de la Salud (OPS). Informe sobre el Estado de Situación Financiera del Seguro de Salud de la Caja Costarricense del Seguro Social. Situación reciente y proyecciones. Washington, EEUU: OPS, 2011.
Orloff, Ann. "Gender in the welfare state". Annual Review of Sociology. Wisconsin, EEUU. University of Wisconsin, 1996: 51-78.

Reguillo, R. "Anclajes y mediaciones del sentido. Lo subjetivo y el orden del discurso un debate cualitativo". Revista Universidad de Guadalajara 17. México. Universidad de Guadalajara, 2000: 50-55.

Sandoval, C. "Contestar la hostilidad antiinmigrante en Costa Rica. Un proyecto de Ciencias Sociales públicas en curso". Inédito.

Sandoval, C. (ed.). El mito roto. Inmigración y emigración en Costa Rica. San José, Costa Rica: Editorial de la Universidad de Costa Rica, 2008.

Schram, S. y Soss, J. "The real value of welfare: why poor families do not migrate". Politics and Society 27 (1). EEuU. Sage Publications, 1999: 39-66.

Van Oorschot, W. "Solidarity towards immigrants in European welfare states". International Journal of Social Welfare 17. New Jersey, EEUU. Wiley-Blackwell, 2008: 3-14.

Vargas Solís, L. Costa Rica: liberalización $y$ ajuste o la autodestrucción del neoliberalismo. San José, Costa Rica: Editorial de la Universidad Estatal a Distancia-EUnED, 2002.

Vargas Solís, L. "La economía costarricense en los inicios del siglo xxı". Costa Rica en los inicios del siglo xxI. A. Santana (ed.). México. Centro de Investigaciones sobre América Latina y el Caribe (CIALC) de la Universidad Nacional Autónoma de México, 2008: 99-126.

Voorend, K. ¿Universal o excluyente? Derechos sociales y control migratorio interno en Costa Rica. Cuidad Autónoma de Buenos Aires, Argentina: CLACSO, 2013.

\section{ENTREVISTAS}

Adrián Jiménez. Dirección de Planificación de la Dirección General de Migración y Extranjería. $1^{\circ}$ de abril de 2013.

Ana Patricia Salas Chacón. Directora Institucional de la Contraloría de 
Servicios de la Caja Costarricense del Seguro Social. 22 de abril de 2013.

Carlos Sandoval. Investigador del Instituto de Investigaciones Sociales (IIS) y Profesor Catedrático de la Universidad de Costa Rica (UCR). 25 de abril de 2013.

Cinthia Mora Izaguirre. Dirección de Integración de la Dirección General de Migración y Extranjería. 03 de abril de 2013.

Douglas Montero. Director Médico Hospital México de la Caja Costarricense del Seguro Social. 23 de mayo de 2013.

Eduardo Flores Castro. Jefe del Área de Coberturas del Estado de la Caja Costarricense del Seguro Social. 24 de abril de 2013.

Funcionario, Dirección Directora del Área de Inspección de la Caja Costarricense del Seguro Social. 29 de abril de 2013.

Funcionario, Jefa de Área de Dirección de Inspección de la Caja Costarricense del Seguro Social. 29 de abril de 2013.

Funcionario, Jefatura del Sub área de Investigación, Dirección de Inspección de la Caja Costarricense del Seguro Social. 29 de abril de 2013.

Giselle Román. Enfermera del Área de Salud Heredia/Cubujuquí de la Caja Costarricense del Seguro Social. 19 de marzo de 2013.
José Luis Quirós. Patólogo Hospital Dr. Max Peralta de la Caja Costarricense del Seguro Social. 28 de agosto de 2013.

Juan Carlos Siles. Ventanilla Preferencial en la Plataforma de Servicios de la Dirección General de Migración y Extranjería. 10 de mayo de 2013.

Juan Pablo Barrantes. Trabajador de Ventanilla del Área de Salud Heredia/Cubujuquí. Caja Costarricense del Seguro Social. 25 de marzo de 2013.

Julio Aragón. Director de Integración de la Dirección General de Migración y Extranjería. $1^{\circ}$ de abril de 2013.

Luis Alonso Serrano. Jefe de Planificación Institucional de la Dirección General de Migración y Extranjería. 02 de mayo de 2013.

Marta Jara. Área de Salud Heredia/Cubujuquí de la Caja Costarricense del Seguro Social. 25 de marzo de 2012.

Trabajadora de Ventanilla. Área de Salud Heredia/Cubujuquí. Caja Costarricense del Seguro Social. 25 de marzo de 2013.

Ventanilla Empresarial. Plataforma de Servicios de la Dirección General de Migración y Extranjería. 10 de mayo de 2013.

Fecha de ingreso: $13 / 01 / 2014$ Fecha de aprobación: 30/05/2014 
